\title{
Reducing murder to manslaughter: whose job?
}

\author{
E Griew Faculty of Law, University of Leicester
}

\section{Author's abstract}

This paper compares two versions of the diminished responsibility defence, which reduces murder to manslaughter: the present statutory formulation and a proposed reformulation. The comparison confirms that evidence such as psychiatrists are commonly invited to give in murder cases takes them beyond their proper role. Paradoxically, although the two formulations mean essentially the same thing, the proposed change of wording must have the practical effect of subduing the psychiatrist's evidence. This conclusion leads to speculation about why psychiatrists are at present allowed so large a function in diminished responsibility cases and to some general observations about the role of the expert in relation to those of judge and jury.

A few years ago the case of one Robinson reached the Court of Appeal in relation to sentence (1). Robinson had been charged with the murder of his wife by stabbing. The marriage had been stormy. Mrs Robinson had needed protection from her husband on earlier occasions; and he had had spells in a mental hospital after domestic incidents (the diagnosis is not revealed). He also drank excessively and this may have contributed to the fatal incident.

Robinson tendered a plea of guilty of manslaughter (not murder) on the ground of diminished responsibility. A consultant psychiatrist had diagnosed 'mild psychopathy' and said that this justified 'a clinical finding that his emotional reactions had been diminished in a way which came within the Homicide Act'. These remarkable words were presumably those of the psychiatrist himself, although they occur in Lawton L J's summary of the case in his judgement. The 'emotional reaction' in question was apparently one of anger; is such a reaction not heightened rather than diminished when it issues in a lethal attack? And what kind of 'clinical finding' is made when responsibility is found diminished (for that is what must have been meant)?

Although Lawton $\mathrm{L} \mathrm{J}$ made no comment on the

\section{Key words}

Diminished responsibility; Homicide Act, 1957; mentally abnormal offender; forensic psychiatry; homicide. language - and I think that that itself is interesting - he was obviously unhappy about the expert's judgement and its reception by the trial judge. The judge had on the strength of it accepted Robinson's plea. For the Court of Appeal Lawton L J said: 'We cannot stress too strongly that these cases of homicide are to be tried by judges and juries and not by psychiatrists'. This remark itself was not crystal-clear.

Perhaps I may ask you to bear this case in mind as I proceed.

\section{Section 2 of the Homicide Act 1957 and a possible reformulation}

In this paper I propose to examine the present formulation of the diminished responsibility defence in order to compare it with the front-runner among proposed reformulations. I shall argue that the two formulations, properly understood, come essentially to the same thing. Yet it will be clear that evidence of the kind regularly given at present could not by any possibility be given if the reformulation proposed were to be adopted. I shall indulge in some speculation about how this can be the case; for it is certainly very strange and seems to require explanation. I shall suggest that the reformulation in question would tie the expert witness more closely to his proper role than the present law in practice does; and in this connection I shall have something to say about the respective roles of different participants in a criminal trial.

Under the present form of the defence a person is guilty of manslaughter rather than of murder if, when he killed, even intentionally, he 'was suffering from such abnormality of mind (whether arising from a condition of arrested or retarded development of mind or any inherent causes or induced by disease or injury) as substantially impaired his mental responsibility for his acts and omissions in doing or being a party to the killing'. It is a common occurrence for an expert witness, in a case in which Section 2 is relied upon, to state his opinion whether the defendant's 'mental responsibility' was 'substantially impaired' or (more shortly) whether he 'was suffering from diminished responsibility'. As long ago as 1967 , in a case on the Obscene Publications Act, Lord Parker C J said that a question put to extract such an opinion was 'technically 
strictly inadmissible' but was nevertheless 'allowed time and time again without objection' (2).

The other formulation to consider is that preferred by the Criminal Law Revision Committee (CLRC) in their report in 1980 on Offences against the Person. It is a modification of the formula proposed five years earlier by the Butler Committee. Under the CLRC version the offence would be manslaughter if the defendant was suffering from a form of mental disorder as defined in the Mental Health Act and 'if, in the opinion of the jury, the mental disorder was such as to be a substantial enough reason to reduce the offence to manslaughter' (3). (I should say that the words 'in the opinion of the jury' seem to me to be surplusage; the provision would mean exactly the same without them.) I take it to be clear that a medical witness would not undertake to say directly whether the mental disorder of which he had given evidence was such as to be a substantial enough reason to reduce the offence to manslaughter. The nearest, I suppose, that he could get to such a statement would be to say, if permitted, that the case is one in which in the old days he would have given an affirmative opinion on diminished responsibility. This, of course, would not be permitted.

The Butler Committee's own suggested rewording of the defence (on which the CLRC were merely marginally improving) would have raised the question whether the defendant's mental disorder 'was such as to be an extenuating circumstance which ought to reduce the offence to manslaughter'. They strangely said of this that it 'would . . . not materially alter the practical effect of the Section' (4). What they may have meant is that the legal effect of the Section would be little changed. This is what I want to establish. But the practical consequences for the defence would be considerable.

\section{Section 2: nonsense or ellipsis}

I begin by considering the language of Section 2(1) free of judicial authority. My point will be, in a word, that it is elliptical almost to the point of nonsense.

'Such abnormality of mind . . . as substantially impaired his mental responsibility for his acts ... '. Two major writers have taken a surprising view of this language. Professor Nigel Walker has read the Section as implying that there are states of mind that 'have something in common' analogous to impairment of a faculty such as hearing or eyesight - namely, 'an impairment of some mental faculty which is called “responsibility". What began', he says, 'as a term for a man's penal status' - he was referring to diminished responsibility in its Scots law cradle - 'had become a psychological concept, although not one that scientific psychologists recognise'(5). Professor Walker does not suggest that the 'concept' he finds in the Section corresponds to any reality. Rather, in order to make sense of the Section, he identifies reference to a creature that does not exist. Professor Herbert Hart is at one point more specific about the meaning of 'mental responsibility' in Section 2. For him it refers to the defendant's 'capacity to control his actions' (6); it is 'the name or description of a psychological condition' (7). Elsewhere, however, he refers to the capacities of 'understanding' and of 'reasoning' as well as of 'control of conduct' and expresses the view that a person's responsibility for his actions in the sense of such 'complex psychological characteristics ... may intelligibly be said to be diminished or impaired' (8). But even if sense could be made of Section 2 by this kind of interpretation, 'capacity to control actions' would be too restricted a translation of 'mental responsibility' for the purpose in hand; and an amalgam of capacities or 'psychological characteristics' is, as an alternative translation, too uncertain to be convincing. Moreover such an interpretation does not fit the language of the Section.

One distinguished psychiatrist recently remarked to me: 'I don't think we know very much about mental responsibility'. He had, I believe, been seduced into thinking that this was a meaningful remark by long experience of being invited, as an expert, to opine about the state of a defendant's 'mental responsibility' - as though it were indeed a specific faculty. My answer should have been: tell me what would count as 'knowledge about' mental responsibility, so that it might enable you to give more authoritative evidence to the effect that it was substantially impaired; what exactly is it about which you seek knowledge? I do not think there is any possible answer. Responsibility (mental or otherwise) for acts refers not to a subject of knowledge but to an evaluative conclusion from that of which knowledge might meaningfully be claimed. It is not something that can itself be known about. This is not to express epistemological pessimism; it is rather to accuse Parliament of pronouncing a kind of nonsense. But as we have to make sense even of nonsense when the legislature speaks, it will be better to refer to Parliament's language as being quite shockingly elliptical and to unpack the ellipsis.

I am offering merely the orthodox view of the use of 'responsibility' in Section 2. It is that, for example, of the two committees I have already referred to. It is the view, to use the language of Butler, that 'mental responsibility' is 'either a concept of law or a concept of morality; it is not a clinical fact relating to the defendant' (9). We are dealing with the degree of a person's responsibility for his or her acts, not (even if such language made sense) with the condition of the responsibility with which his or her acts are done. The outcome of a sufficiently favourable view of the evidence will be diminished liability (which is a legal conclusion) based upon an assessment of reduced culpability (which is a moral conclusion). But of course the word 'impaired' is quite unsuited to express this.

The wording is altogether a disgrace. Parliament has clumsily packed together two ideas. They are respectively signalled by the words impaired ... mental' on one side of the word 'responsibility' and the words 'for his acts' on the other side. The result is that 
the word 'responsibility' does double duty; so, perhaps, does 'substantially'. If you force the compacted ideas apart you get something like this: $\mathrm{He}$ had an abnormality of mind (of appropriate origin). This had a substantial adverse effect upon one or more relevant functions or capacities (of perception, judgement, feeling, control). In the context of the case this justifies the view that culpability is substantially reduced. The outcome is diminished liability: manslaughter. Now pack that together again in a different form: his abnormality of mind is of such consequence in the context of this offence that his legal liability for it ought to be reduced. And compare that with the version of the judges, advising the Butler Committee out of court: 'the defendant has shown recognisably abnormal mental symptoms and ... in all the circumstances it would not be right to regard his act as murder in the ordinary sense'; so 'it is open to the jury to bring in a verdict of manslaughter' (10).

In court, however, the judges have not explicitly recognised that there is anything odd about the language of Section 2. The reported cases reveal few attempts to explain the Section; they give no sign of any special judicial discomfort in the face of Parliament's performance; and they achieve, it seems to me, almost nothing in the way of elucidation. The most elaborate, as well as the most influential, judgement is that of Lord Parker C J in Byrne (11). 'The expression "mental responsibility for his acts",' he said, 'points to a consideration of the extent to which the accused's mind is answerable for his physical acts . . . I have always felt this to be somewhat worse than the original; the notion of an 'answerable' mind is amazing. But at least 'answerability' cannot be a function; so that when Lord Parker immediately adds that the consideration of the extent of the answerability 'must include a consideration of the extent of [the accused's] ability to exercise will power to control his physical acts,' he is surely himself using together a collection of ideas such as I have suggested are compacted in the Section.

Elsewhere the judges occasionally speak as though they are being helpful, but without managing to help very much. In Lloyd (12), for example, the Court of Appeal approved Ashworth J's direction on 'substantially': 'Substantial does not mean total, that is to say, the mental responsibility need not be totally impaired, so to speak, destroyed altogether. At the other end of the scale substantial does not mean trivial or minimal'. There is no sign, though, that the learned judge gave any suggestion to the jury of what this 'mental responsibility' was of which trivial impairment, total impairment (so to speak) or something in between might be found.

But recognition of the hidden complexity of the statutory language, if not explicit, is implicit both in the case law and in much judicial practice under the Section. To show this I need to take up at last the topic of expert evidence. In practice the expert is permitted to say whether in his opinion the defendant's mental responsibility was substantially impaired. It is widely (though not universally) recognised that in giving such $\underset{F}{\stackrel{m}{F}}$ an opinion the witness exceeds his competence. There $\bar{\delta}$ are various ways in which this may be true. First, $\stackrel{\Rightarrow}{\Rightarrow}$ 'substantially' (whatever it refers to) raises a question $\stackrel{\bar{s}}{\rightarrow}$ of degree which, if it comes to a contest, only a jury can? solve. An analogy would be 'grievous bodily harm'. A 흠 surgeon can describe a fracture, can speak of the time $\frac{\bar{\rho}}{\overline{0}}$ it will take to mend and of the probable nature of any $\stackrel{\mathbb{Q}}{\Omega}$ residual disability; but he cannot pronounce the bodily harm to be 'grievous'. So with 'substantial's impairment. Secondly, the opinion that responsibility? was substantially impaired seems to be an opinion as to $\overrightarrow{\vec{\omega}}$ how the case should be decided; and there is a rule of $\stackrel{ }{\circ}$ the common law that even an expert is incompetent to pronounce on the 'ultimate issue'. Thirdly (and conclusively), there is the fact that the matters to which $\vec{N}$ as an expert the witness speaks are not the only matters $\overrightarrow{-}$ relevant to the assessment of substantial impairment of $\infty$ responsibility. The jury 'are entitled and indeed bound 음 to consider not only the medical evidence but the evidence upon the whole of the facts and circumstances $\frac{3}{2}$ of the case' (as it was put by the Privy Council in Walton (13)). It seems that the jury may set the defendant's? abnormality and its effects upon him (on which the $\vec{\infty}$ expert's help is essential (14)) against the character of ? the offence. This enables the jury to behave very variously. In one familiar kind of case they may say: we understand and partly sympathise with this offence, $\frac{\partial}{\partial}$ and the slight evidence of abnormality is enough to persuade us to reduce liability. In another they may $\stackrel{\mathbb{Q}}{\mathbb{Q}}$ say: we so abhor this offence that not even the $\overrightarrow{\vec{P}}$ undoubted abnormality will suffice to reduce liability. 응 It is true that the abnormality may be so clear, gross and plainly causative that a conviction of murder 'cannot be supported having regard to the evidence', as the Criminal Appeal Act used to say; it would be 'unsafe or unsatisfactory', as the Act now has it. In 0 such a case the conviction would be quashed, as the Court of Criminal Appeal showed in Matheson (15) as 8 early as 1958 . But this does not contradict what I have $₹$ said of the jury function; it merely shows that the court 을 will occasionally regard a murder verdict as one which $>$ the jury could not reasonably reach.

In practice, of course, the jury function is often $\bar{N}$ performed by prosecution and judge, when a plea of ${ }^{\circ}$ guilty of manslaughter is accepted. And sometimes, as $N$ strikingly in the Sutcliffe case (16), the court reserves $\tilde{N}$ the function for the jury to perform; the plea, although unanimously supported by the doctors, is rejected.

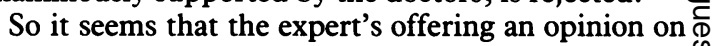
this particular ultimate issue, although with the court's ? permission, is inconsistent with the courts' own 무 implicit view of what Section 2 means. It is that view which justified the Court of Appeal's shorthand $\stackrel{\odot}{\oplus}$ expostulation in Robinson: 'these cases . . . are to be $\stackrel{\mathbb{Q}}{\varrho}$ tried by judges and juries and not by psychiatrists' (1). 으

The judges, then, do not like to say in clear terms 8 that the language of Parliament is close to gibberish or even to castigate it expressly as elliptical. But their view. of the jury function, their practice in the consideration 
of proffered pleas and their evidence to the Butler Committee all confirm that the effect on responsibility referred to by Section 2 is not merely a matter of impairment of function or capacity. It is also a conclusion about the level of appropriate liability. The true 'ultimate issue' is the issue of what that liability ought to be. On this, it is plain, no witness can properly give an opinion.

In the exercise of the evaluative function the court or jury is left almost without guiding principle. A 'popular language' test of 'partial insanity or being on the border-line of insanity', which Lord Parker appeared to espouse in Byrme (17), was soon discredited as a general test by the Privy Council in Rose (18). Although the Privy Council itself referred to it in Walton (13), the Court of Appeal has had to point out recently that a trial judge had been wrong to use it in a case of reactive depression (19). And indeed, if a defendant did have to reach 'the border-line of insanity', even understood 'in its broad popular sense' (18) (whatever that is), countless decisions under Section 2 would become incomprehensible.

The effect of the abnormality of mind must, as we know, be more than trivial or minimal at one end of the scale; Matheson (15) may operate at the other end. In between, the jury (or the court) is left to freewheel its way to a discrimination between murder and manslaughter in the individual case. If it allocates the case to the manslaughter category, it has, of course, done only part of the job of assessing responsibility. For now the task of disposal occurs. Continuing mental disorder may justify a hospital order or, if that is not indicated or appropriate secure provision cannot be made, a life sentence. A probation order - even a discharge - may reflect minimum or nil culpability. In other cases Section 2's own tariff applies. In Chambers (20) in 1983 the Court of Appeal said in terms that one whose 'mental responsibility' was 'substantially impaired' may retain 'a very substantial amount of responsibility for his acts'. The dominant sense of the key word here is surely 'culpability'. A number of reported cases show the courts, through prison sentences of different lengths, fine-tuning the responsibility issue that has been only partly concluded by the verdict, or the acceptance of the plea, of manslaughter (21). The sentence in Chambers was eight years.

\section{The two formulations compared}

The short point to which I have been tending is that Section 2 of the Homicide Act, properly understood, and the CLRC's revision of the Butler proposal for reformulation of the diminished responsibility defence, come essentially to the same thing. I can now set the latter version alongside my reading of Section 2 . The basis of a Section 2 defence is 'abnormality of mind' as limited by the words in parenthesis; the basis of the revised defence is a form of 'mental disorder' as defined in the Mental Health Act. There is a difference here which would make an interesting subject for discussion; and it has obliged me to qualify with the word 'essentially' the proposition that the two formulations 'come to the same thing'. But this difference is not material for my purpose. I am concerned with the essential nature of the defence and with the functions of those engaged in the trial. For this purpose what I emphasise in the CLRC's preferred version is the notion that 'the mental disorder was such as to be a substantial enough reason to reduce the offence to manslaughter'. Why is it reason enough? Because, I take it, of its effect (or at least its supposed effect) on function or capacity and thence (by a leap we can all make but none of us explain) on perceived culpability. If this is right, the CLRC version is simply a summary of my own stretched-out reading of the tightly-packed language of Section 2. Neither version, of course, indicates the minimum culpability required for murder or the greatest culpability that ought properly to be reflected in a mere manslaughter verdict. Nor could either do so; there is no calibration of culpability. Both formulas leave the matter to the jury, or to the court exercising the jury function, as one for the exercise of an obscure intuition.

I have already asserted, without fear of contradiction, that no witness could express an opinion that the defendant's mental disorder was 'a substantial enough reason to reduce the offence to manslaughter'. How is it, then (if the two formulations come essentially to the same thing) that witnesses are allowed to testify directly to a substantial impairment of the defendant's 'mental responsibility for his acts'? The question is not adequately answered by acknowledging that the testimony is strictly inadmissible. If I am right about the true meaning of the witness's assertion, it is one that he not only should not but in the nature of things cannot make - any more than he could diagnose negligence or breach of contract. Yet he makes it 'time and time again without objection'. How does this come about? Let me sketch some rather speculative contributions towards an explanation. I shall mention five points at once and reserve a sixth for my final words.

First, not all judges have understood that Section 2 raises an ethico-legal rather than a clinical issue; and some judges, I believe, still do not. A High Court judge for whom I have the greatest respect recently asked me, in effect, who could say whether responsibility was substantially impaired if a psychiatrist could not.

Secondly, some judges may prefer, in effect, to take the psychiatrists' word for it because of their own difficulty with the concepts and language of psychiatry. In one of the reported cases (admittedly in 1962) the trial judge told the jury that 'schizophrenia' means 'a split mind'; and, referring to a psychiatrist's evidence that the defendant had 'a psychopathic personality without psychosis', said 'that puzzles me'. Edmund Davies $J$ in the Court of Criminal Appeal said that 'no summing-up could be . . . more helpful' (22). 
Thirdly, even a court with a good understanding of the evidence might doubt the capacity of the jury to understand it and to use it for the purpose of the judgement that has to be made. A preference for leaving the discrimination between murder and manslaughter to the legally incompetent rather than to the technically or intellectually incompetent would be understandable.

Fourthly, there is sometimes a great difficulty involved in makıng a satisfactory connection between abnormality and impaired capacity; and there is always an irresoluble difficulty in proceeding from impairment of capacity to diminution of liability (23). The Section 2 ellipsis glosses over these difficulties. Unpacking the ellipsis draws attention to them. The courts have not perhaps been keen to do this. So the language of Section 2 is not too closely examined. The Section can conveniently be treated as raising one issue rather than a complex set of issues. And the psychiatrist speaks to the one issue - for he must, after all, speak.

Fifthly, it seems clear that many judges have welcomed the opportunity to achieve through Section 2 a rather greater modification of the law of murder than the Section strictly justifies. Some cases described as 'reactive depression', for example, might be impossible to bring within Section 2 if clinical description and statutory interpretation were both rigorously conducted. The killing performed in grief or from compassion is quietly taken out of the murder category when the terse judgement 'diminished responsibility' is offered by the expert to a receptive court.

\section{Implications}

Suppose the CLRC formula were enacted, so that evidence had to be directed to proof of a form of mental disorder which was a substantial enough reason to reduce the offence to manslaughter. I should like, finally, to consider the evidential implications of such a reform, for to do so may illuminate present practice. The true function of the expert witness would not change; but it would be brought into sharper focus and would, I think, be more exactly discharged.

In a trial by jury involving expert evidence and a value judgement, the roles of judge, expert and jury ought to be clearly distinguished. I will loosely call them the roles, respectively, of prescription, description and decision, and illustrate them by reference to the issues under a reformed Section 2 . The judge, from his reading of the Section and of authoritative decisions on it, prescribes the elements legally required for a verdict of manslaughter. If a question arises whether some evidence given is evidence of mental disorder within the meaning of the Mental Health Act and therefore of the revised defence, it is for the judge to say. He advises the jury, in the light of the evidence, of the questions they must ask themselves and of the answers that would entail or permit a particular verdict. The descriptive role of the expert is to report his own clinical observations; to $\underset{5}{=}$ attribute significance to those observations and to relevant reports on which he can rely, according to the current wisdom of his discipline; to advise on how that $\stackrel{\vec{P}}{+}$ significance relates to any relevant statutory category $\bar{C}$ that is expressed in the language of his discipline $\left(I \frac{\bar{\sigma}}{\bar{N}}\right.$ suppose 'mental illness', as one example of 'mental $\frac{\text { के }}{\sigma}$ disorder', is such a category; 'disorder or disability of $\underset{\complement}{\overparen{Q}}$ mind' is presumably not); and - if possible - to offer an assessment of the likely effect upon function or $\vec{O}$ capacity of any condition to which he testifies. The jury's decisions in such a case are several: did the $\vec{\omega}$ symptoms etc referred to by the expert exist? Do they justify the conclusion that a relevant form of mental disorder existed? How badly affected was the defendant? The final decision is: does that degree of $\stackrel{\vec{v}}{-}$ dysfunction or incapacity justify reduction of liability to manslaughter in the context of this case? More $\infty$

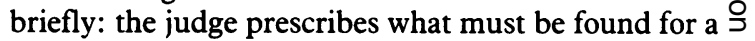
particular result; the expert provides the material for $\vec{z}$ relevant findings; the jury makes, or does not make, those findings.

The present language of Section 2, of course, $\vec{\oplus}$ encourages role confusion. The judge cannot in terms of that language identify a distinct task for the jury. By the same token the Section's terms can be taken to suggest that the witness can go beyond description. Not so with the CLRC formula. I have argued that that formula does not change the law (except by $\frac{\AA}{\Phi}$ substituting 'mental disorder' for 'abnormality of $\varrho$ mind'). But it fully exposes the solecism which we saw $\overline{\overrightarrow{0}}$ in Robinson at the outset (1), and precludes repetition of it; never again would a witness be able to claim that he had made 'a clinical finding that [the defendant's] emotional reactions had been diminished in a way which came within the Homicide Act'. Henceforth the psychiatrist's evidence cannot be more than descriptive; it cannot be conclusory - except as to the existence of a recognised form of mental disorder.

Moreover, the description must be such as will enable the jury so to apprehend the condition of the defendant that they can pass directly from that $\frac{D}{O}$ apprehension to a judgement as to the appropriate verdict. For the witness's own conclusion - whatever $N$ he might mean by it - of a substantial impairment of $N$ responsibility would not be available as a bridge N between his description and their judgement.

This may be a heavy demand. It would put diagnostic labelling relatively at a discount, except $\stackrel{\circ}{\leftarrow}$

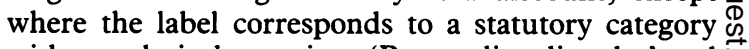
with a technical meaning. 'Personality disorder' and 'immaturity' may be distinctly less helpful labels when unattached to a conclusion of impaired responsibility (sounding as it does like a higher-level statutory $\frac{\AA}{\mathbb{D}}$ diagnosis). At a corresponding premium will be, first, $\frac{\varrho}{\circ}$ information, conveyed so far as possible in the vernacular, about the phenomena of which any such $\delta$ label may be a summary; and secondly, any help that the witness can give the jury towards a grasp of the behavioural implications of those phenomena in the 
context of the offence. The demand is, in effect, that the psychiatrist should have not only the technical skills of his own discipline, including developed powers of insight and empathy, but also a novelist's power to convey his own insight and empathy to others. If he can do this, those others can perform their job - of reducing, or declining to reduce, murder to manslaughter.

The jury have that function in the case of a contest. The fact that they are provided with no real criterion for its discharge suggests my sixth explanation of the failure of the courts to make a critical analysis of Section 2. Quite simply: the judges may not be happy about setting the jury adrift to find 'a substantial enough reason to reduce murder to manslaughter'. What do the jury know of the distinction between the two? If they ask how manslaughter is to be recognised, they must be told that it is their verdict which will identify it. This is a very strange situation. I think that strictly the law is the same today; but I can understand that the judges may hesitate to make it explicit and may not relish the proposed reform.

Edward Griew is Professor of Law and Dean of the Faculty of Law in the University of Leicester.

\section{References}

(1) $R$ v Robinson (1979) 1 Cr App R (S) 108.

(2) DPP v A and BC Chewing Gum Ltd [1968] 1 QB 159 at 164.
(3) Criminal Law Revision Committee, Fourteenth Report (Cmnd 7844), para 93.

(4) Report of the Committee on Mentally Abnormal Offenders (Cmnd 6244) para 19. 17.

(5) Crime and insanity in England, Vol 1. Edinburgh: Edinburgh University Press, 1968: 152.

(6) Hart L A. Punishment and responsibility. Oxford: Oxford University Press, 1968: 202.

(7) See reference (6): 220.

(8) See reference (6): 227-228.

(9) See reference (4): para 19.5, also reference (3) para 91, and, by Williams $\mathrm{G}$, a member of both committees, Textbook of criminal law (2nd ed). London: Stevens, 1983: 686.

(10) See reference (4): 19.4 .

(11) $R$ v Byrne [1960] 2 QB 396 at 403.

(12) $R$ v Lloyd [1967] 1 QB 175.

(13) Walton $\mathrm{v}$ The Queen [1978] AC 788 at 793.

(14) $R$ v Dix (1981) 74 Cr App $R 306$.

(15) $R$ v Matheson (1958) 42 Cr App R 145.

(16) The so-called 'Yorkshire Ripper' case (unreported). See Burn G. '... somebody's husband, somebody's son'. London: William Heinemann Ltd, 1984.

(17) See reference (11) at 404.

(18) Rose v The Queen [1961] AC 496 at 507.

(19) $R$ v Seers Times 1984 May 5.

(20) $R$ v Chambers (1983) $5 \mathrm{Cr}$ App $\mathrm{R}$ (S) 190. CfR v Fewsbury, 1981, $3 \mathrm{Cr}$ App R (S) 1 (3 years for 'not an inconsiderable degree of responsibility').

(21) See for example $R$ v Norman (1982) 146 JPN 147 (5 years); $R$ v Davis, 1984, Crim LR 245 (2 years).

(22) $R$ v.fennion [1962] 1 All ER 689.

(23) $C f$ Wootton B. Social science and social pathology. London: George Allen and Unwin Ltd, 1959: 239-240. 